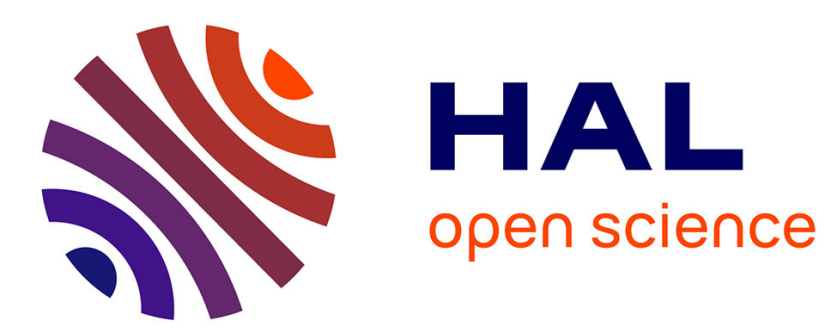

\title{
Receiver Autonomous Integrity Monitoring of GNSS Signals for Electronic Toll Collection
}

\author{
Daniel Salós, Anaïs Martineau, Christophe Macabiau, Bernard Bonhoure, \\ Damien Kubrak
}

\section{- To cite this version:}

Daniel Salós, Anaïs Martineau, Christophe Macabiau, Bernard Bonhoure, Damien Kubrak. Receiver Autonomous Integrity Monitoring of GNSS Signals for Electronic Toll Collection. IEEE Transactions on Intelligent Transportation Systems, 2014, 15 (1), pp.94-103. 10.1109/TITS.2013.2273829 . hal01207658

\section{HAL Id: hal-01207658 \\ https://hal-enac.archives-ouvertes.fr/hal-01207658}

Submitted on 19 Dec 2015

HAL is a multi-disciplinary open access archive for the deposit and dissemination of scientific research documents, whether they are published or not. The documents may come from teaching and research institutions in France or abroad, or from public or private research centers.
L'archive ouverte pluridisciplinaire HAL, est destinée au dépôt et à la diffusion de documents scientifiques de niveau recherche, publiés ou non, émanant des établissements d'enseignement et de recherche français ou étrangers, des laboratoires publics ou privés. 


\title{
Receiver Autonomous Integrity Monitoring of GNSS signals for Electronic Toll Collection
}

\author{
Daniel Salós, Anaïs Martineau, Christophe Macabiau, Bernard Bonhoure, and Damien Kubrak
}

\begin{abstract}
Various Road User Charging (RUC) mechanisms are used to control the traffic and its resulting pollution, as well as revenue sources for reinvestment in the road infrastructure. Among them, Electronic Toll Collection (ETC) systems based on user positions estimated with Global Navigation Satellite Systems (GNSS) are particularly attractive due to their flexibility and reduced roadside infrastructure in comparison to other systems like tollbooths. Because GNSS positioning may be perturbed by different errors and failures, ETC systems, as liability critical applications, should monitor the integrity of GNSS signals in order to limit the use of faulty positions and the consequent charging errors. The integrity monitoring systems have been originally designed for civil aviation, so they need to be adapted to the ETC requirements. This paper studies the use of Receiver Autonomous Integrity Monitoring (RAIM), which are algorithms run within the GNSS receiver, and therefore easier to tune to ETC needs than other systems based on external information. The Weighted Least Squares Residuals (WLSR) RAIM used in civil aviation is analyzed, and an algorithm modification for ETC is proposed. Simulations demonstrate that the proposed RAIM algorithm has a superior level of availability over civil aviation based RAIM procedures, particularly in urban environments.
\end{abstract}

Index Terms-Electronic Toll Collection (ETC), Global Navigation Satellite Systems (GNSS), Receiver Autonomous Integrity Monitoring (RAIM), urban environment.

\section{INTRODUCTION}

I NTEGRITY of Global Navigation Satellite Systems (GNSS) is defined as a measure of the trust that can be placed in the correctness of the information supplied by the navigation system [1]. The concept of GNSS integrity was originally developed in the civil aviation framework as part of the International Civil Aviation Organization (ICAO) requirements for using GNSS in the Communications, Navigation and Surveillance / Air Traffic Management (CNS/ATM) system. In particular, civil aviation standards specify a set of minimum accuracy, availability, integrity and continuity performance on the GNSS Signal-in-Space (SIS) for each operation and phase of flight [2]. Nevertheless,

Manuscript received December 19, 2012. This work was supported in part by the Centre National d'Etudes Spatiales (CNES) and Thales Alenia Space.

D. Salós, A. Martineau, and C. Macabiau are with the Ecole Nationale de l'Aviation Civile (ENAC), Toulouse, France (e-mail: salos, martineau, macabiau@ recherche.enac.fr).

B. Bonhoure is with the CNES, Toulouse, France.

D. Kubrak is with Thales Alenia Space, Toulouse, France. standalone GPS cannot meet the stringent civil aviation requirements, and, specifically, the GPS SIS integrity standard [3] does not assure integrity as specified by the ICAO. For this reason, various augmentation systems have been developed to allow the use of GPS within the ICAO requirements. These systems are classified according to their infrastructure into Ground, Satellite, and Aircraft Based Augmentation Systems (GBAS, SBAS and ABAS).

The need for reliable satellite navigation with integrity monitoring is not limited to the civil aviation field. Two types of applications need GNSS integrity: Safety-of-Life (SoL) applications, in which undetected navigation errors may endanger life, and liability critical applications, in which positioning errors may have negative legal or economic consequences [4]. A number of integrity-driven positioning applications have vehicular or pedestrian users and take place in urban and rural environments [5]. A few examples of these applications are Electronic Toll Collection (ETC), train control, dangerous or valuable goods transport survey and emergency calls.

Each application has its own integrity constraints and needs an integrity monitoring technique adapted to its specifications. This paper focuses on Electronic Toll Collection (ETC) systems in urban and rural environments based on GNSS positioning. GNSS-based ETC schemes are particularly interesting because they are free-flow (pay-as-you-drive), highly flexible systems with a reduced quantity of roadside infrastructure. Moreover, satellite navigation is, together with $5.8 \mathrm{GHz}$ microwave and GSM-GPRS communication systems, one of the technologies the European Union recommends for the European Electronic Toll Service (EETS) [6]. As of 2012, toll systems for freight transport using GPS as primary positioning technology are already operational in German and Slovak highways and national roads [7] [8].

GNSS-based ETC systems are liability critical applications because excessive and uncontrolled positioning errors may lead to incorrect toll invoices. The act of levying a toll lower than it should be is denoted undercharging and implies a loss of revenue, whereas the act of levying a toll higher than it should is known as overcharging and may originate user claims. Thus, ETC specifications should bound the maximum acceptable rate of undercharging and overcharging errors in order to assure the quality of the service to both users and the toll operator. For this reason, GNSS integrity monitoring is a key element of ETC systems which assures that positioning 
errors are below the specified limits, detecting unacceptably large errors.

Different solutions have been studied to monitor the navigation integrity in urban environments, often hybridizing GNSS with dead-reckoning and map-matching techniques [9][10][11]. The aim of this paper is to present an integrity monitoring algorithm that only uses GNSS measurements, consisting of a snapshot RAIM tailored to the needs of ETC in urban environments. This approach reduces the complexity of the on-board equipment and avoids memory problems due to error propagation in recursive loops, as well as the thorough characterization of errors due to non-GNSS components required by integrity mechanisms. The Least Squares Residuals (LSR) RAIM has been chosen because it is well known in civil aviation and is commonly taken as baseline algorithm [12]. A digital map is used to charge the user, but not in the integrity monitoring process.

The paper is organized as follows. First, the GNSS-based ETC scheme with integrity monitoring is explained in section II. Afterwards, the WLSR RAIM used in civil aviation and a modified version adapted to the ETC needs in urban environments are analyzed in Sections III and IV. The characteristics of both RAIM algorithms are compared in section V, and, finally, section VI presents their performance calculated via simulations.

\section{GNSS-BASED ELECTRONIC TOLL COLLECTION SYSTEMS}

The discrete road links charging toll scheme defined in the ISO standard [13] is studied. The geo-fencing approach is followed, in which the tolled road network is split into segments defined by virtual perimeters. The areas within the perimeters are denoted geo-objects and constitute the basic charging units, that is, users are charged the price associated to a geo-object whenever they are detected inside it. Each geoobject's fee is set individually and can be designed according to different factors like the user category, the time of the day or the traffic state. Moreover, distance-based charge is possible when geo-objects are defined as road portions between intersections, with only one entrance and one exit. Geo-fencing is an appropriate approach for GNSS-based ETC applications that allows highly flexible systems with a low number of roadside infrastructures.

The main task of the ETC system is to decide whether a user has driven through a road segment or not, and charge him if he has. This decision, known as geo-object recognition, can be taken as a function of the number of user positions lying inside the geo-object boundaries. In order to bound the maximum rate of erroneous geo-object recognitions (i.e. erroneously charged segments), only positions declared valid by the integrity monitoring system are used. Moreover, only independent positions are taken to eliminate the effects of the positioning error temporal correlation. In this context, two position estimates are independent when they produce independent integrity monitoring outputs. The correlation time depends on the GNSS receiver type as well as other constraints within the local environment. Summarizing, the proposed road segment charging algorithm is:

$$
\text { charge segment } \Leftrightarrow N_{\text {valid INSIDE }} \geq N_{\text {Th }}
$$

where $\mathrm{N}_{\text {valid INSIDE }}$ is the number of valid and independent positions inside the geo-object, and $\mathrm{N}_{\mathrm{Th}}$ is the geo-object recognition threshold.

The integrity monitoring systems have been originally designed to meet the civil aviation requirements, so they need to be adapted to the ETC specifications. From the various possible integrity monitoring systems, this work studies the Receiver Autonomous Integrity Monitoring (RAIM), which are algorithms run within the GNSS receiver that monitor integrity thanks to redundant pseudorange measurements. Since RAIM algorithms, as opposed to GBAS or SBAS, do not rely on external information, they can be easily adapted to the ETC requirements and to the multi-frequency, multiconstellation case. This paper considers the use of SBAS corrections, but not of its integrity service because it has been designed mainly to assure the civil aviation requirements.

Only the integrity of the horizontal positioning is required to be monitored for ETC application. For each estimated position, RAIM provides a Horizontal Protection Level (HPL), defined as a circular area centered at the user real position that is assured to contain the estimated position with a probability equal to or higher than $\left(1-\mathrm{P}_{\mathrm{MD}}\right)$, where the maximum allowed probability of missed detection $\mathrm{P}_{\mathrm{MD}}$ is a design parameter. The Horizontal Alert Limit (HAL) is the maximum allowed HPL and depends on the road network topography, and can be set as the half of the distance between roads [14].

\section{WLSR RAIM FOR CIVIL AVIATION}

\section{A. Introduction}

The Least Squares Residuals (LSR) RAIM [15], together with the solution separation method [16], is one of the RAIM algorithms most frequently used in civil aviation. Moreover, the parity matrix RAIM [17] and the range comparison technique [18] are equivalent to the LSR RAIM [19].

The design of the LSR RAIM assumes that pseudorange nominal errors are modeled as independent zero-mean Gaussian distributions with the same variance. This was an acceptable condition when pseudorange errors were dominated by the Selective Availability (SA), but at present pseudorange errors are better described as independent zero-mean Gaussian distributions with variance dependent upon several factors like the signal modulation or the satellite elevation angle. In this case, the Weighted Least Squares Residuals (WLSR) RAIM is used [20].

\section{B. Algorithm Design}

The WLSR RAIM considers the following linear pseurorange measurement model: 


$$
\Delta Y=H \cdot \Delta X+E
$$

where $\Delta Y\left[N_{s} \times 1\right]$ is the linearized measured pseudorange vector, $\mathrm{H}\left[\mathrm{N}_{\mathrm{s}} \times \mathrm{N}_{\mathrm{u}}\right]$ is the observation matrix, $\Delta \mathrm{X}\left[\mathrm{N}_{\mathrm{u}} \times 1\right]$ is the linearized navigation state vector, and $E\left[N_{s} \times 1\right]$ is the pseudorange error vector. $\mathrm{N}_{\mathrm{s}}$ is the number of pseudoranges, and $N_{u}$ is the number of unknowns in $\Delta X$.

Two possible pseudorange error scenarios are assumed, namely fault-free and faulty. In the fault-free case, pseudorange measurements are disturbed only by nominal errors, modeled as zero-mean independent Gaussian distributions with covariance matrix $\Sigma$. In the faulty case, apart from nominal errors, there is one biased pseudorange measurement:

$$
E=\varepsilon+B
$$

where $\varepsilon\left[\mathrm{N}_{\mathrm{s}} \times 1\right]$ is the nominal error vector and $\mathrm{B}\left[\mathrm{N}_{\mathrm{s}} \times 1\right]$ is the bias vector:

$$
B=\left[0, \cdots, b_{i}, 0, \cdots, 0\right]^{T}
$$

with $b_{i}=0$ in the fault-free case. The probability of simultaneous faulty pseudoranges is assumed to be negligible.

The WLSR RAIM monitors the integrity of the navigation state vector calculated with the Weighted Least Squares Estimator (WLSE):

$$
\begin{gathered}
\Delta \hat{X}=A \cdot \Delta Y \\
A=\left(H^{T} \Sigma^{-1} H\right)^{-1} H^{T} \Sigma^{-1}
\end{gathered}
$$

The aim of RAIM algorithms is to detect positioning errors exceeding the alert limit within the required probabilities of missed and false alarm. Since positioning errors are not directly measurable, the WLSR RAIM calculates, thanks to the residual vector $(\mathrm{R})$, a measurable scalar test statistic (t) that provides information about pseudorange measurement errors. The test statistic is computed as the Weighted Sum of Squared Errors (WSSE):

$$
\begin{gathered}
t=W S S E=R^{T} \Sigma^{-1} R=\Delta Y^{T} \Sigma^{-1}(I-B) \Delta Y \\
R=\Delta Y-H \Delta \widehat{X}=(I-B) \Delta Y=(I-B) E \\
B=H\left(H^{T} \Sigma^{-1} H\right)^{-1} H^{T} \Sigma^{-1}
\end{gathered}
$$

The test statistic calculated in (7) follows a chi-squared distribution in the fault free case, and a non-central chisquared one in the faulty case:

$$
t \sim \begin{cases}\chi_{k}^{2} & \text { if } E \sim N(0, \Sigma) \\ \chi_{k, \lambda}^{2} & \text { if } E \sim N(B, \Sigma)\end{cases}
$$

In both fault-free and faulty scenarios the test statistic's number of degrees of freedom $(\mathrm{k})$ is the number of redundant pseudorange measurements:

$$
k=N_{s}-N_{u}
$$

The chi-squared non-centrality parameter $(\lambda)$ introduced by a faulty measurement, which depends on the bias magnitude and on the nominal errors, is:

$$
\lambda=(I-B)_{i i} \cdot b_{i}^{2} / \sigma_{i}^{2}
$$

where $\sigma_{i}^{2}$ is the nominal error variance of the biased pseudorange, and $(\cdot)_{\mathrm{ii}}$ is the $\mathrm{i}^{\text {th }}$ element of the $\mathrm{i}^{\text {th }}$ row.

Because we are interested in the protection against positioning failures, but the WLSR RAIM detects faults via the test statistic, the relationship between the horizontal positioning error $\left|\mathrm{e}_{\mathrm{H}}\right|$ and $\mathrm{t}$ needs to be investigated. In the faulty case, there is a linear relationship between the pseudorange bias projection in the horizontal error domain $\left(\left|b_{\mathrm{H}}\right|\right)$ and the square root of the test statistic $\lambda$, characterized by the slope parameter:

$$
\begin{gathered}
\left|b_{H}\right|=\text { slope }_{i} \cdot \sqrt{\lambda} \\
\text { slope }_{i}=\sigma_{i} \cdot \sqrt{\left(A_{N, i}^{2}+A_{E, i}^{2}\right) /(I-B)_{i i}}
\end{gathered}
$$

where $\mathrm{A}_{\mathrm{N}, \mathrm{i}}^{2}$ and $\mathrm{A}_{\mathrm{E}, \mathrm{i}}^{2}$ are the $\mathrm{i}^{\text {th }}$ element of the rows of matrix $A$ in (6) corresponding to the state vector horizontal position components. The slope, which varies from one satellite to another, is an indicator of the relationship between the effect of a pseudorange bias in the test statistic and in the positioning error. A pseudorange bias leading to a given noncentrality parameter $\lambda$ will have the highest impact on the positioning error when it appears in the satellite with the highest slope.

The statistic components of the test statistic and the navigation state estimation errors, caused by nominal errors, are uncorrelated [21], i.e. $\operatorname{cov}(\mathrm{t}, \mathrm{e})=0$. Therefore, the relationship between $\mathrm{t}$ and $\left|\mathrm{e}_{\mathrm{H}}\right|$ at a given epoch can be described as a 2D random variable with the following PDF:

$$
\operatorname{PDF}\left(\sqrt{t},\left|e_{H}\right|\right)=\operatorname{PDF}(\sqrt{t}) \cdot \operatorname{PDF}\left(\left|e_{H}\right|\right)
$$

Once the test statistic and its relationship with the position error have been defined, the remaining RAIM parameters can be derived. These are the fault detection threshold (Th), the minimum detectable non-centrality parameter $\left(\lambda_{\text {det }}\right)$ and the Horizontal Protection Level (HPL). Fig. 1 depicts the different RAIM design process steps in the $\mathrm{t}^{1 / 2}$ against $\left|\mathrm{e}_{\mathrm{H}}\right|$ plane, in a similar way as in [22]. The bidimensional PDF has been represented by an equiprobable line for clarity reasons.

\section{Design parameters $\left(P_{M D}, P_{F A}\right)$}

The WLSR RAIM is designed to meet a maximum allowed probability of missed detection $\left(\mathrm{P}_{\mathrm{MD}}\right)$ and of false detection $\left(\mathrm{P}_{\mathrm{FD}}\right)$. If the RAIM only has fault detection and not exclusion functions, any missed or false detection results in a missed or false alarm, and the maximum allowed probability of missed alarm $\left(\mathrm{P}_{\mathrm{MA}}\right)$ and false alarm $\left(\mathrm{P}_{\mathrm{FA}}\right)$ are equal to $\mathrm{P}_{\mathrm{MD}}$ and $\mathrm{P}_{\mathrm{FD}}$ respectively. A RAIM algorithm with only a fault detection function is considered, so the design parameters used throughout this work are $\mathrm{P}_{\mathrm{MD}}$ and $\mathrm{P}_{\mathrm{FA}}$. 


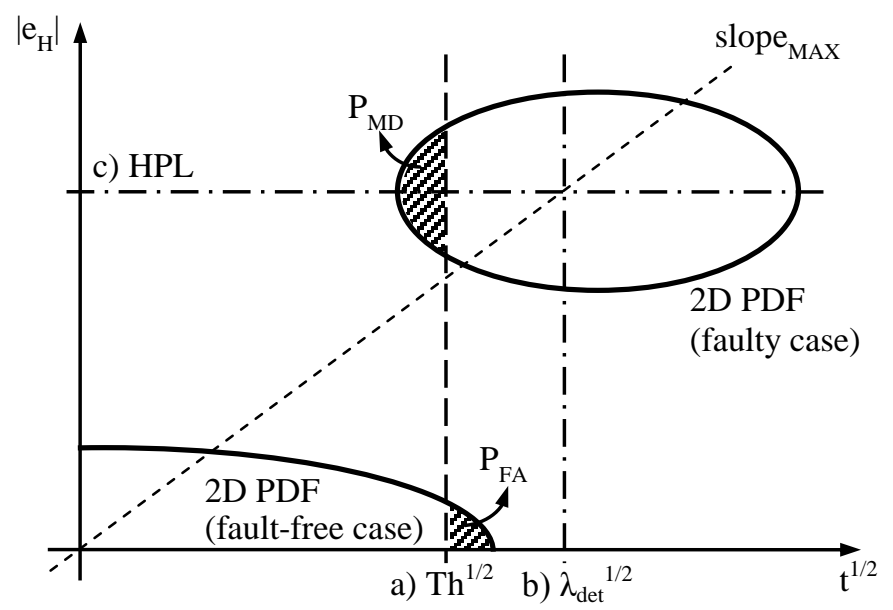

Fig. 1. WLSR RAIM design process:

a) Fault detection threshold (Th).

b) Minimum detectable non-centrality parameter $\left(\lambda_{\text {det }}\right)$.

c) Horizontal Protection Level $\left(\mathrm{HPL}=\operatorname{slope}_{\mathrm{MAX}} \cdot \lambda_{\operatorname{det}}^{1 / 2}\right)$.

\section{Failure Detection Threshold (Th)}

The WLSR RAIM detects a failure whenever the test statistic exceeds a threshold (Th). The threshold is chosen in order to assure the fault detection probability in fault-free conditions, i.e. one minus the cumulated density function of a chi-squared function evaluated at the threshold value:

$$
P_{F A}=p\left\{t>T h \mid t \sim \chi_{k}^{2}\right\}=1-C D F_{\chi_{k}^{2}}\{T h\}
$$

Therefore, Th is a function of $\mathrm{P}_{\mathrm{FA}}$ and $\mathrm{k}$, which in turn depends on the number of pseudoranges $\mathrm{N}_{\mathrm{s}}$.

\section{Minimum Detectable Non-Centrality Parameter $\left(\lambda_{\text {det }}\right)$}

In the faulty case, the test statistic $\lambda$ increases with the bias size as in (12). The minimum detectable non-centrality parameter $\left(\lambda_{\text {det }}\right)$ is the $\lambda$ that results in a missed detection rate equal to $\mathrm{P}_{\mathrm{MD}}$ for the threshold calculated in (16):

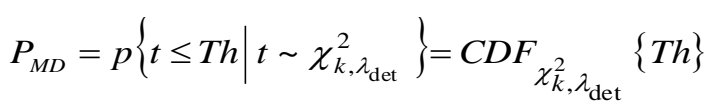

Therefore, $\lambda_{\text {det }}$ is a function of $\mathrm{P}_{\mathrm{MD}}$, $\mathrm{k}$ (which depends on $\mathrm{N}_{\mathrm{s}}$ ) and Th (which also depends on $\mathrm{P}_{\mathrm{FA}}$ ).

\section{Horizontal Protection Level (HPL)}

The HPL is calculated as the projection in the position domain of the pseudorange bias that would generate a noncentrality parameter equal to $\lambda_{\text {det }}$ in the satellite with the maximum slope ( slope $_{\mathrm{MAX}}$ ):

$$
H P L=\text { slope }_{\text {MAX }} \cdot \sqrt{\lambda_{\mathrm{det}}}
$$

The rationale of the HPL calculation of (18) is the following. The positioning error $\left|e_{\mathrm{H}}\right|$ is distributed approximately centered around $\left|b_{H}\right|$, if the bias is sufficiently large. Let us consider a pseudorange bias in the maximumslope satellite with a magnitude such that the test statistic's non-centrality is equal to $\lambda_{\text {det }}$. The probability that the RAIM algorithm does not detect this pseudorange bias and that the positioning error is larger than the HPL is approximately $\mathrm{P}_{\mathrm{MD}} / 2$. The probability of missed detection decreases if the biased pseudorange is in other satellite with a lower slope. Larger biases lead to higher $\lambda_{\text {det }}$, so they are always detected with a probability below $\mathrm{P}_{\mathrm{MD}}$. Smaller bias magnitudes have smaller $\lambda_{\text {det }}$, which sets the probability of not detection over $\mathrm{P}_{\mathrm{MD}}$. Fortunately, they also lead to lower positioning errors that offset the higher non-detection probability, resulting in a probability of missed detection of errors exceeding the HPL of less than $\mathrm{P}_{\mathrm{MD}}$. Nevertheless, in some cases, especially with low slopes, this may not hold [22].

\section{Algorithm Implementation at the GNSS Receiver}

The algorithm run within the receiver consists of two modules, i.e. the RAIM availability check and the Fault Detection (FD) (Fig. 2). The FD could be replaced by a Fault Detection and Exclusion (FDE) module.

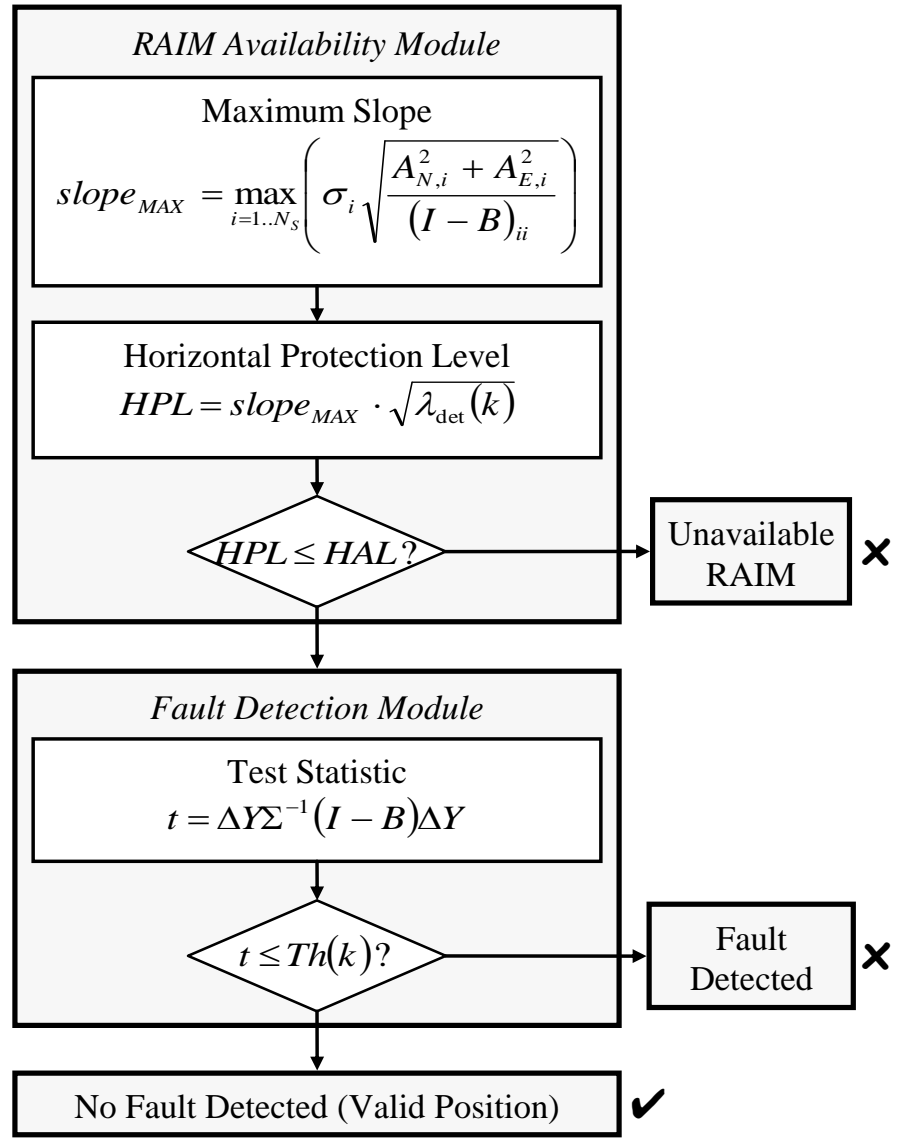

Fig. 2. WLSR RAIM algorithm with Fault Detection capabilities run within the GNSS receiver.

First, at each epoch, the slope of each pseudorange measurement is calculated thanks to the observation matrix and the nominal error covariance matrix. The HPL is computed afterwards with the maximum slope and the corresponding chi-squared non-centrality parameter. If the HPL exceeds the HAL, RAIM is not available because it cannot monitor integrity with the required $\mathrm{HAL}, \mathrm{P}_{\mathrm{MD}}$ and $\mathrm{P}_{\mathrm{FA}}$. 
In this case, the integrity cannot be monitored, so the estimated position is not valid for its use in ETC.

If the HPL is equal to or lower than the HAL, the RAIM is available and proceeds to check whether the estimated position is faulty or not. The test statistic is computed with the linearized pseudorange measurements, the observation matrix and the nominal error covariance matrix. If the test is higher than the corresponding detection threshold, a fault is detected and the position cannot be used in ETC. When the test is lower than the threshold, the position is valid for ETC.

The values of $\lambda_{\text {det }}$ and Th depend on $\mathrm{P}_{\mathrm{MD}}, \mathrm{P}_{\mathrm{FA}}$ and the number of redundant range measurements $k$. They do not depend on current measurements, so they can be computed offline and stored in the receiver as look-up tables.

The WLSR RAIM can optionally perform FDE in order to reduce service interruptions. This module tries to eliminate the biased pseudorange measurement whenever a fault is detected. If after the fault exclusion HPL $\leq \mathrm{HAL}$ and $\mathrm{t} \leq \mathrm{Th}$, the position estimated without the biased pseudorange is valid for ETC. A possible fault exclusion technique creates $\mathrm{N}$ subgroups of $\mathrm{N}-1$ range measurements each; assuming that there is only one faulty pseudorange, the FD module will detect a fault in each subgroup except in the one excluding the faulty measurement. The FDE module needs at least two redundant range measurements.

\section{MODIFIED WLSR RAIM FOR ELECTRONIC TOLL COLLECTION}

\section{A. Motivation and Rationale of the Modified WLSR RAIM}

User/satellite geometry in reduced satellite visibility scenarios like urban environments is likely to be much worse than in the open-air scenarios commonly found in civil aviation. This fact generally increases the Dilution Of Precision (DOP), which degrades the positioning accuracy. Another consequence of bad user/satellite geometries is the augmentation of the maximum slope, which in turn increases the HPL calculated as in (18), and consequently degrades the WLSR RAIM availability (which also depends on the HAL). Therefore, a GNSS-based ETC system that monitors integrity with the WLSR RAIM in challenging environments with reduced visibility is likely to have a low number of valid positions per road segment, and consequently a high missed geo-object recognition rate. The aim of this section is to present a modified WLSR RAIM suitable for ETC applications that improves the availability rate in environments with reduced satellite visibility without increasing the effective missed detection rate and therefore the toll liability risk.

According to (1), a road segment is charged to the user when the number of independent positions declared valid by the RAIM inside the geo-object is at least equal to the recognition threshold. The WLSR RAIM may not declare valid a position because it is not available, or because it has detected a failure, regardless of whether it is a correct or a false detection (see Fig. 2). The aim of the modified WLSR
RAIM described in this section is to maximize the number of valid positions in the fault-free scenario.

The modified RAIM is designed to assure a constant $\mathrm{P}_{\mathrm{MD}}$ in order to set a known maximum probability that a faulty position inside the geo-object is declared valid when the user is actually outside it. As opposed to civil aviation, ETC systems do not require continuity, so their RAIM algorithms do not necessarily need to assure a maximum allowed $\mathrm{P}_{\mathrm{FA}}$.

Given constant values of $\mathrm{P}_{\mathrm{MD}}$, slope ${ }_{\mathrm{MAX}}$ and $\mathrm{k}$, the HPL can be decreased by increasing the $\mathrm{P}_{\mathrm{FA}}$ (Fig. 3):

$$
P_{F A, b}<P_{F A, a} \Rightarrow H P L_{b}>H P L_{a}
$$

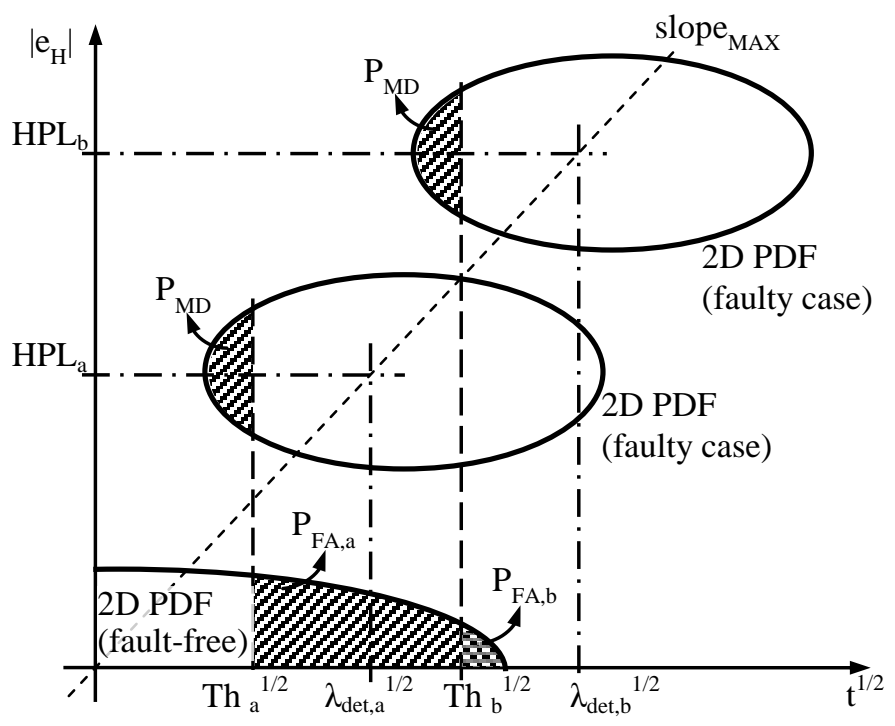

Fig. 3. Effect of the $P_{F A}$ in the WLSR RAIM with a fixed $P_{M D}$ and a number of chi-squared degrees of freedom $\mathrm{k}$.

The main idea behind the modified WLSR RAIM algorithm is to adapt the $\mathrm{P}_{\mathrm{FA}}$ to the maximum slope variations to provide a tradeoff between RAIM availability and false alarms, without any restriction on the maximum allowed $\mathrm{P}_{\mathrm{FA}}$.

\section{B. Algorithm Design}

The objective is to design a RAIM algorithm with the WLSR test statistic described in (7), that maximizes the probability that a fault-free position (affected only by nominal errors) is declared valid, i.e. the RAIM is available and does not detect a fault. Since the WLSR test statistic is used, the formulas (2-18) also apply for the modified WLSR RAIM. Moreover, the algorithm must assure that the probability of not detecting, in the faulty scenario, a positioning error larger than the HAL is always equal to or lower than a fixed value $\mathrm{P}_{\mathrm{MD}}$.

The first design objective is equivalent to finding the detection threshold $(\mathrm{Th})$ that maximizes the probability of not detecting a failure in the fault-free scenario, subject to the condition that the RAIM is available:

$$
T h=\underset{T h}{\arg \max } p\left\{t<T h \mid\left(t \sim \chi_{k}^{2}\right) \&(H P L \leq H A L)\right\}
$$


Given fixed values of $\mathrm{P}_{\mathrm{MD}}$ and $\mathrm{k}$, the HPL expression of (17) is a monotonically increasing function of Th. Hence, the detection threshold that maximizes (20) is the one that results in an HPL equal to the HAL.

Therefore, the proposed RAIM procedure is designed to provide a constant HPL equal to the HAL. The minimum detectable chi-squared non-centrality parameter that corresponds to an HPL equal to HAL is derived from (18):

$$
\lambda_{\mathrm{det}}=\left(H A L / \text { slope }_{\text {MAX }}\right)^{2}
$$

The detection threshold that maximizes (20) is derived from equation (17) with the $\lambda_{\operatorname{det}}$ calculated in (21):

$$
T h=C D F^{-1} \chi_{k, \lambda_{\text {det }}}^{2}\left\{P_{M D}\right\}
$$

The fault detection algorithm can already be run once the detection threshold has been calculated. For performance analysis purposes, the $\mathrm{P}_{\mathrm{FA}}$ provided at each instant can be derived from equation (16) with the Th calculated in (22):

$$
P_{F A}=1-C D F_{\chi_{k}^{2}}\{T h\}
$$

The resulting algorithm is a Constant-Probability-ofDetection (CPOD) RAIM [23] with the particularity of not having a maximum allowed $\mathrm{P}_{\mathrm{FA}}$. This modified WLSR RAIM is always available (HPL=HAL), but very high slopes lead to high false alarm probabilities. A fault-free estimated position is declared valid by the RAIM with a probability of:

$$
P_{\text {valid }}=1-P_{F A}=C D F_{\chi_{k}^{2}}(T h)
$$

\section{Algorithm Implementation at the GNSS Receiver}

The algorithm run at the receiver can be either the Fault Detection (FD) module (Fig. 4), or the Fault Detection and Exclusion (FDE) module. There is no RAIM availability check module because the HPL is set to be always equal to the HAL.

First, at each epoch, the slope of each pseudorange measurement is computed as in the standard WLSR RAIM. Afterwards, the minimum detectable chi-squared noncentrality parameter is calculated with the HAL and the maximum slope.

The detection threshold is then calculated with (22) as the value for which the Cumulative Density Function (CDF) of a non-central chi-squared distribution with $\mathrm{k}$ degrees of freedom and non-centrality $\lambda_{\text {det }}$ is equal to $\mathrm{P}_{\mathrm{MD}}$.

Since Th depends on current measurements, its exact value cannot be computed offline and stored like in the WLSR RAIM used in civil aviation. Nevertheless, it is possible to create a look-up table of Th as a function of $\mathrm{k}$ and discrete values of $\lambda_{\text {det }}$ (for a given $\mathrm{P}_{\mathrm{MD}}$ ).

Finally, the test statistic is computed as in (7) with the linearized pseudorange measurements, the observation matrix and the nominal error covariance matrix.

The estimated position is declared valid for its use in ETC if the test statistic does not exceed the threshold, and it is rejected if a fault is detected.

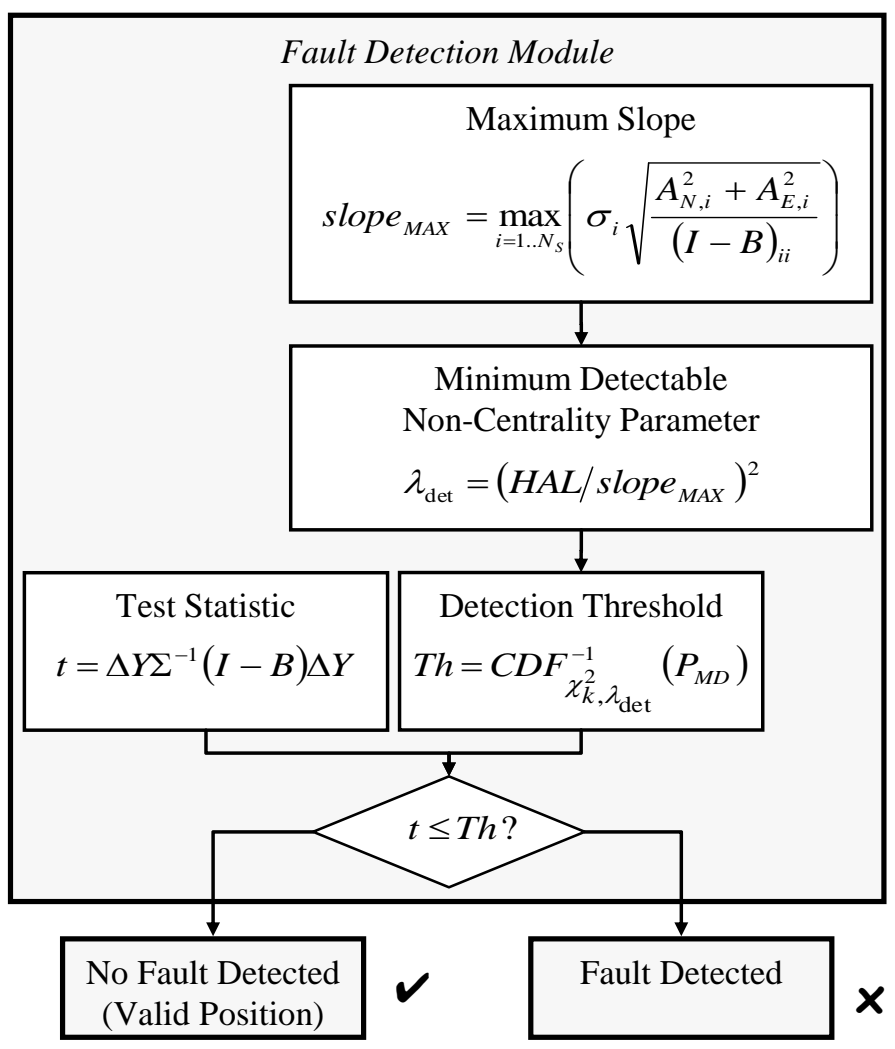

Fig. 4. Modified WLSR RAIM algorithm run within the GNSS receiver.

\section{COMPARISON BETWEEN THE WLSR RAIM USED IN CIVIL AVIATION AND THE MODIFIED ALGORITHM For ETC}

Both WLSR RAIM algorithms monitor the integrity of the position estimated applying the WLSE to the linearized GNSS pseudorange measurements, assuming a known nominal pseudorange error model and a single biased pseudorange in the faulty scenario (equations (2-6)). The two algorithms use the same test statistic described in (7-12), related with the positioning error as given in $(13,14)$. Consequently, the relationships (15-18) depicted in Fig. 1 between $\mathrm{P}_{\mathrm{MD}}, \mathrm{P}_{\mathrm{FA}}, \mathrm{Th}$, $\lambda_{\text {det }}$ and HPL apply to both algorithms. The computational cost of the proposed algorithm is similar to the civil aviation one if it is implemented with a look-up table of discrete values of Th.

Both WLSR RAIM algorithms assure a detection rate equal to $\mathrm{P}_{\mathrm{FA}}$ in the fault-free scenario. Note that, assuming that nominal errors do not cause positioning failures, any detection in fault-free scenario is a false detection. Both algorithms also assure that, in the faulty scenario with one biased pseudorange, the missed detection rate of positioning errors exceeding the HPL is equal to or lower than $\mathrm{P}_{\mathrm{MD}}$.

The main difference between both algorithms resides in the fact that the WLSR RAIM used in civil aviation provides a time-variant HPL and constant $\mathrm{P}_{\mathrm{MD}}$ and $\mathrm{P}_{\mathrm{FA}}$, while the modified algorithm provides a time-variant $\mathrm{P}_{\mathrm{FA}}$ and constant $\mathrm{P}_{\mathrm{MD}}$ and HPL (equal to the HAL). 
Fig. 5 illustrates the false detection probability in the faultfree scenario, and the probability that a positioning error larger than HAL, i.e. a positioning failure, is not detected in the faulty scenario with a biased pseudorange such that the noncentrality parameter is $\lambda_{\text {det }}$ (the shaded area). It is important to note that the actual probability of undetected positioning failures in the faulty scenario depends on the slope of the biased pseudorange, and on the bias magnitude that moves the bidimensional PDF along the slope.

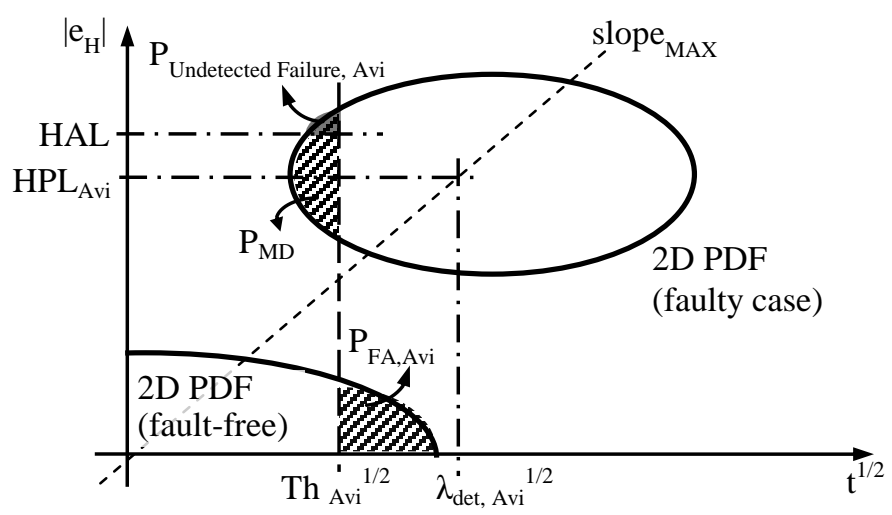

a) WLSR RAIM used in civil aviation (subscript Avi. stands for aviation)

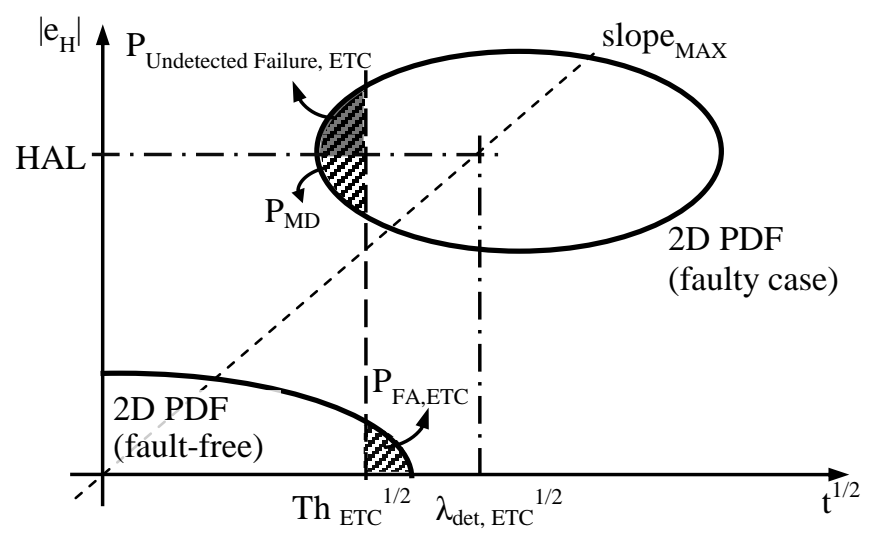

b) WLSR RAIM modified for Electronic Toll Collection

Fig. 5. Graphical example of the undetected failure probability in the faulty case with a biased pseudorange such that $\lambda=\lambda_{\text {det }}$, and of the false alarm probability in the fault-free scenario.

The WLSR RAIM for civil aviation is designed to provide at each epoch the lowest HPL that meets the required $\mathrm{P}_{\mathrm{MD}}$ and $\mathrm{P}_{\mathrm{FA}}$. The integrity is monitored only if HPL $\leq \mathrm{HAL}$. The RAIM detects positioning errors exceeding the HPL with a probability higher than $1-\mathrm{P}_{\mathrm{MD}}$, so the lower the HPL, the lower the actual missed detection probability of positioning failures larger than the HAL (the shaded area in Fig. 5). Positioning errors between HPL and HAL are treated as positioning failures and are detected with a missed detection probability below $\mathrm{P}_{\mathrm{MD}}$. In the fault-free case, the algorithm constantly provides the maximum allowed false detection rate $\mathrm{P}_{\mathrm{FA}}$. Therefore, the standard WLSR RAIM minimizes the probability of undetected positioning failures at the expense of the false detection rate.
The WLSR RAIM for ETC is designed to provide at each epoch, in the fault-free case, the lowest probability of false alarm $\mathrm{P}_{\mathrm{FA}}$ that meets the required $\mathrm{P}_{\mathrm{MD}}$ and HAL. The algorithm constantly provides an HPL equal to the HAL. For this reason, the actual probability of detection probability of positioning failures larger than the HAL (the shaded area in Fig. 5) is less conservative than in the original algorithm. Therefore, the modified WLSR RAIM minimizes the probability of false detection, at the expense of a less conservative probability of undetected positioning failures.

High maximum slopes due to bad user/satellite geometries result in high HPL in the civil aviation RAIM procedure and in high $\mathrm{P}_{\mathrm{FA}}$ in the modified algorithm. This means that positions rejected by the civil aviation algorithm due to RAIM unavailability can be monitored with the new algorithm at the cost of increasing the $\mathrm{P}_{\mathrm{FA}}$. Fig. 6 shows the probability of rejecting a fault free position for both RAIM procedures with one redundant pseudorange measurement $(\mathrm{k}=1)$, as a function of the ratio $\mathrm{HAL} /$ slope $_{\text {MAX }}$. Let us remember that a position is declared valid when the RAIM is available and does not detect a failure. The availability condition for the RAIM used in civil aviation can be rewritten using (18) as:

$$
\sqrt{\lambda_{\mathrm{det}}} \leq H A L / \text { slope }_{\text {MAX }}
$$

Following the example of Fig. 6, equations (16) and (17) give a value of $\lambda_{\operatorname{det}}^{1 / 2}=7.5$ with $\mathrm{P}_{\mathrm{MD}}=10^{-3}, \mathrm{P}_{\mathrm{FA}}=10^{-5}$ and $\mathrm{k}=1$. In that case, the RAIM is available if HAL/slope MAX $_{\text {is larger }}$ than 7.5, and unavailable if it is not. When the RAIM is available, the false detection is constantly $\mathrm{P}_{\mathrm{FA}}=10^{-5}$, while when it is unavailable integrity cannot be monitored and the position is always rejected.

On the other hand, the modified WLSR RAIM presents a decreasing false alarm probability as HAL/slope ${ }_{\text {MAX }}$ increases. For instance, continuing with the case depicted in Fig. 6, a ratio HAL/slope ${ }_{\text {MAX }}$ equal to 7 would cause the original RAIM to be unavailable and to reject the position, but the modified algorithm is able to monitor integrity and validate the position with a probability of $1-10^{-4}$.

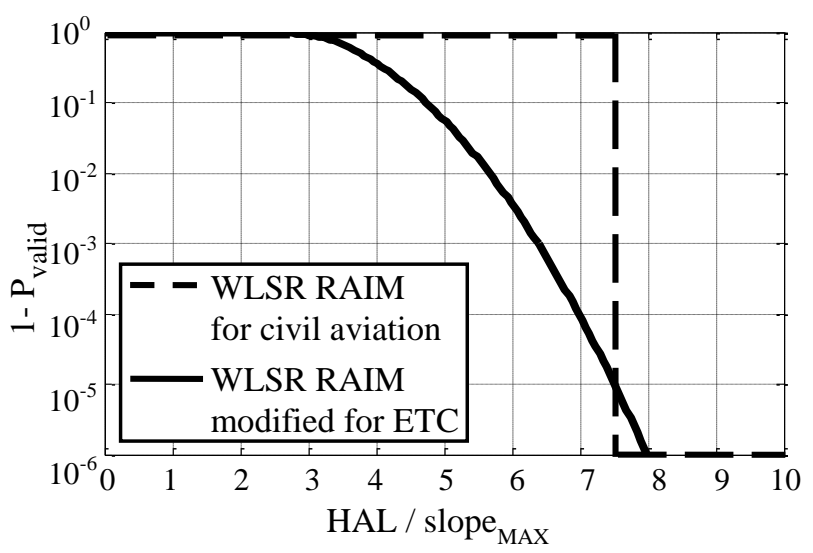

Fig. 6. Probability of not declaring valid a fault-free position. Configuration: $\mathrm{k}=1, \mathrm{P}_{\mathrm{MD}}=10^{-3}$, RAIM for civil aviation $\mathrm{P}_{\mathrm{FA}}=10^{-5}$. 
The modified WLSR RAIM is suitable for applications like ETC that need the maximum number of positions assured to be within a given HAL with a given $\mathrm{P}_{\mathrm{MD}}$, rather than a continuity requirement. Other studies have addressed the use of RAIM algorithms with flexible $\mathrm{P}_{\mathrm{FA}}$ in applications with continuity constraints like civil aviation [24].

\section{Simulation Results}

This section presents the navigation system performance; the final toll charging performance should include other possible failures like geo-object database errors. The WLSR RAIM performance depends on the design parameters (HAL, $\mathrm{P}_{\mathrm{MD}}$, and, in the classic algorithm, $\mathrm{P}_{\mathrm{FA}}$ ) and on the maximum slope, which in turn depends on the environment, i.e. the user/satellite geometry. The RAIM performance in rural and urban environments has been obtained via simulations.

The simulated scenario consists of a user moving at a constant velocity of $50 \mathrm{~km} / \mathrm{h}$ along the axis of a 20-metre wide straight street. Buildings are generated statistically at both sides of the street as in Table I, separated by a gap with a probability of $10^{-1}$. The nominal 24-satellite GPS and 27satellite Galileo constellations are simulated, and only line-ofsight satellites with an elevation angle over $5^{\circ}$ are assumed to be received by the user. The simulation length is set to 72-hour to cover approximately all possible GPS \& Galileo satellite ground track combinations. Data is sampled every second.

TABLE I

SIMULATED ENVIRONMENTS

\begin{tabular}{|c|c|c|}
\multicolumn{3}{|c|}{ SIMULATED ENVIRONMENTS } \\
\hline \hline Environment & Urban & Rural \\
\hline \multirow{2}{*}{ Building height $\left(\mathrm{H}_{\mathrm{B}}\right)$} & $\begin{array}{c}\mathrm{H}_{\mathrm{B}} \sim \tilde{\mathrm{N}}(15 \mathrm{~m}, 3 \mathrm{~m}) \\
4 \mathrm{~m} \leq \mathrm{H}_{\mathrm{B}} \leq 25 \mathrm{~m}\end{array}$ & $\begin{array}{c}\mathrm{H}_{\mathrm{B}} \sim \tilde{\mathrm{N}}(6 \mathrm{~m}, 1.5 \mathrm{~m}) \\
4 \mathrm{~m} \leq \mathrm{H}_{\mathrm{B}} \leq 20 \mathrm{~m}\end{array}$ \\
\hline \multirow{2}{*}{ Building width $\left(\mathrm{W}_{\mathrm{B}}\right)$} & $\mathrm{W}_{\mathrm{B}} \sim \mathrm{N}(20 \mathrm{~m}, 25 \mathrm{~m})$ & $\mathrm{W}_{\mathrm{B}} \sim \mathrm{N}(20 \mathrm{~m}, 25 \mathrm{~m})$ \\
& $\mathrm{W}_{\mathrm{B}} \geq 10 \mathrm{~m}$ & $\mathrm{~W}_{\mathrm{B}} \geq 10 \mathrm{~m}$ \\
\hline \multirow{2}{*}{ Gap width $\left(\mathrm{W}_{\mathrm{G}}\right)$} & $\mathrm{W}_{\mathrm{G}} \sim \mathrm{N}(15 \mathrm{~m}, 25 \mathrm{~m})$ & $\mathrm{W}_{\mathrm{G}} \sim \mathrm{N}(15 \mathrm{~m}, 25 \mathrm{~m})$ \\
& $\mathrm{W}_{\mathrm{G}} \geq 10 \mathrm{~m}$ & $\mathrm{~W}_{\mathrm{G}} \geq 10 \mathrm{~m}$ \\
\hline \hline
\end{tabular}

Three GNSS receivers are studied. A single frequency GPS L1 C/A with a wideband front-end of $16 \mathrm{MHz}$ augmented with SBAS corrections, a single frequency dual constellation GPS \& Galileo L1/E1 BOC $(1,1)$ with a $4-\mathrm{MHz}$ frontend filter augmented with SBAS corrections, and a dual frequency GPS \& Galileo L1/E1MBOC \& L5/E5a BPSK(10) with a 14-MHz and a $20-\mathrm{MHz}$ frontend filter respectively. The first configuration will give the performance of current high performance receivers, and the GPS \& Galileo configurations with modernized signals represent the performance attainable in a near future. In the dual constellation case, a modernized SBAS capable to correct Galileo signals is assumed.

Various charging metrics can be used to define the ETC required performance [13], but numerical values of these metrics are not standardized. This section considers, as in [14], a fault-detection WLSR RAIM configuration with $\mathrm{P}_{\mathrm{MD}}=5 \cdot 10^{-5}$ and two possible values of $\mathrm{P}_{\mathrm{FA}}, 5 \cdot 10^{-3}$ and $5 \cdot 10^{-5}$. The HAL depends on the road topology; in this paper numerical examples are given for HAL of 25 and 50 meters [14].

A pseudorange nominal measurement model suitable for integrity applications in urban environments is used. Following a similar approach as in [1][2], the pseudorange error is calculated as the result of various independent error sources: ionosphere and troposphere delays, tracking loops errors, multipath and ephemeris and satellite clock errors. The model is summarized as follows. The ionospheric residual error model is that of the civil aviation standards for single frequency GPS and SBAS [2], and zero for dual frequency users. The troposphere residual error model standardized for civil aviation is used [2]. The tracking loop errors are modeled as in [25], considering a 1-Hz DLL, a 20-ms integration time, a dot-product discriminator and a carrier to noise ratio $\mathrm{C} / \mathrm{N}_{0}$ of $30 \mathrm{~dB}$. The multipath error model is detailed in [26]. Finally, the GNSS are assumed to be sufficiently modernized to assure ephemeris and satellite clock nominal errors with a standard deviation of $85 \mathrm{~cm}$. The total pseudorange error model is a zero-mean Gaussian distribution with the standard deviation $\left(\sigma_{\mathrm{PSR}}\right)$ of Fig. 7. It is important to note that $\sigma_{\mathrm{PSR}}$ is expected to decrease with higher $\mathrm{C} / \mathrm{N}_{0}$, especially in dual frequency receivers that eliminate the ionospheric delay at the cost of amplifying the thermal noise error.

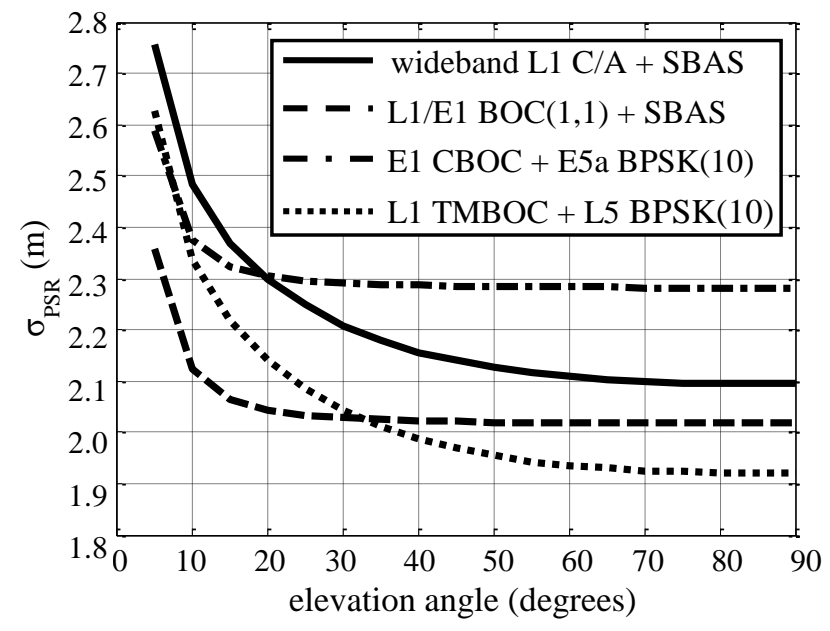

Fig. 7. Pseudorange nominal error model.

The number of visible satellites and the HPL distribution obtained with the classic WLSR RAIM remarks the relevance of the environment and of the number of constellations (Fig.8 and Fig. 9). Both dual constellation receivers show similar performances. For instance, in the dual constellation case and a HAL of $50 \mathrm{~m}$, the percentage of epochs in which a RAIM configured with $\mathrm{P}_{\mathrm{MD}}=5 \cdot 10^{-5}$ and $\mathrm{P}_{\mathrm{FA}}=5 \cdot 10^{-3}$ is available decreases from almost $100 \%$ in the rural environment to approximately $55 \%$ in the urban one. In the GPS case, it decreases from $50 \%$ to around $7 \%$. Lower $\mathrm{P}_{\mathrm{MD}}$ or $\mathrm{P}_{\mathrm{FA}}$ would decrease the availability rate.

Fig. 10 shows the CDF of the number of valid positions for a dual constellation user during a 30-s trajectory trough a road segment. The modified WLSR RAIM provides the highest number of valid positions. 


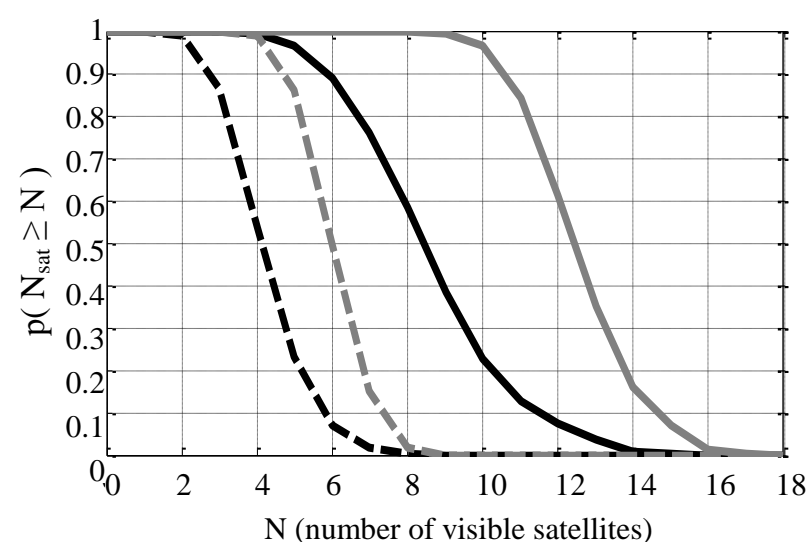

\begin{tabular}{l|l}
\hline \hline - - GPS & Grey: rural environment \\
- GPS \& Galileo & Black: urban environment \\
\hline \hline
\end{tabular}

Fig. 8. Distribution of visible satellites.

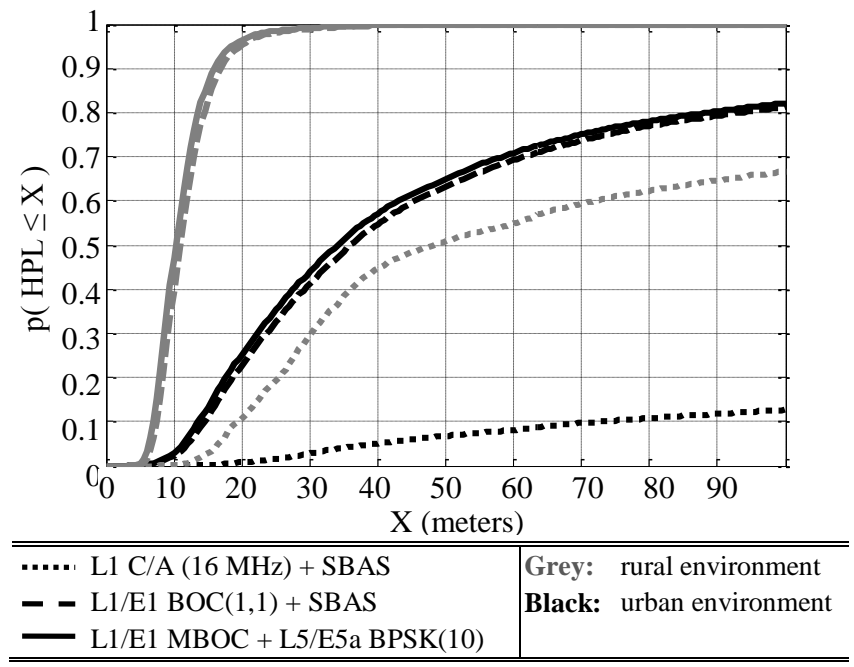

Fig. 9. CDF of the HPL obtained with the civil aviation WLSR RAIM with the following constant parameters: $\mathrm{P}_{\mathrm{FA}}=5 \cdot 10^{-3}$ and $\mathrm{P}_{\mathrm{MD}}=5 \cdot 10^{-5}$.

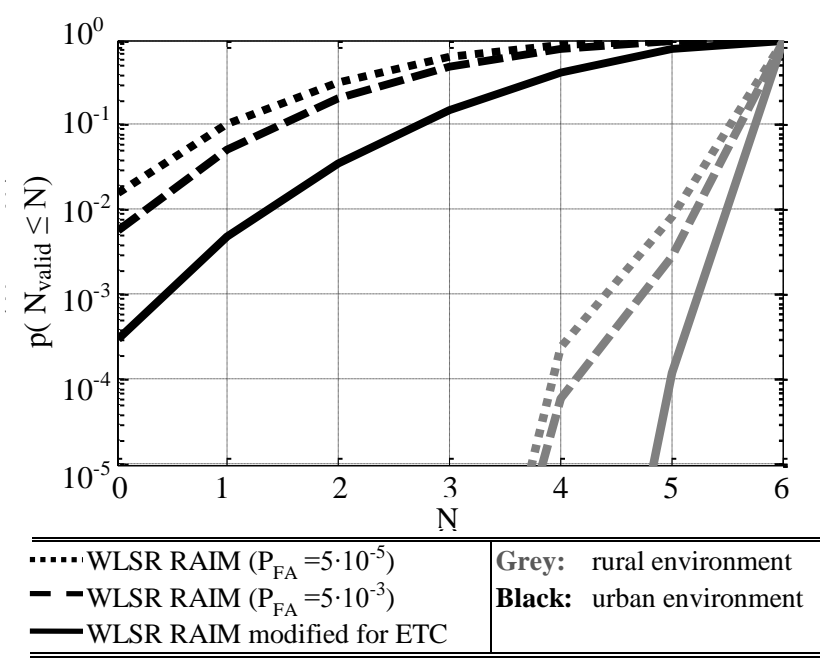

Fig. 10. CDF of the number of positions declared valid by the RAIM in a trajectory of 30 seconds for L1/E1 MBOC \& L5/E5a BPSK(10) users $\left(\mathrm{P}_{\mathrm{MD}}\right.$ $=5 \cdot 10^{-5}, \mathrm{~T}_{\mathrm{c}}=5 \mathrm{~s}, \mathrm{HAL}=25 \mathrm{~m}$ ).

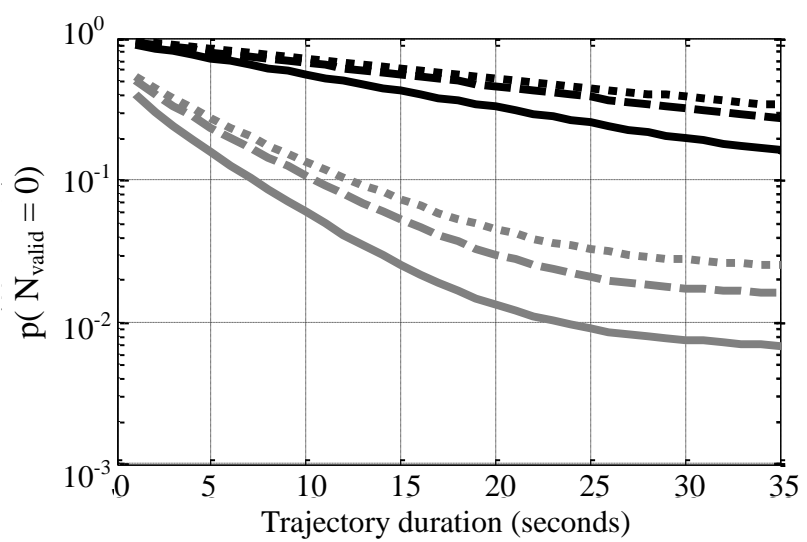

a) Wideband L1 C/A + SBAS users, HPL $=50$ meters.

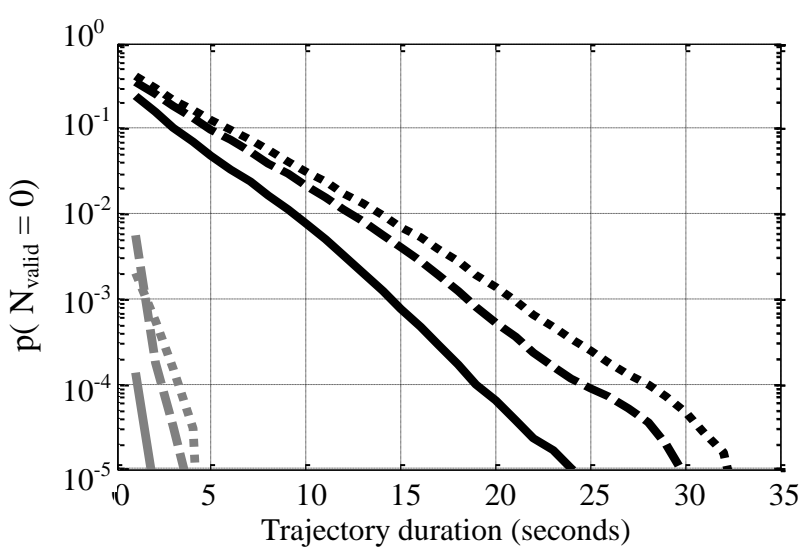

b) L1/E1 MBOC \& L5/E5a BPSK(10) users, HPL $=50$ meters.

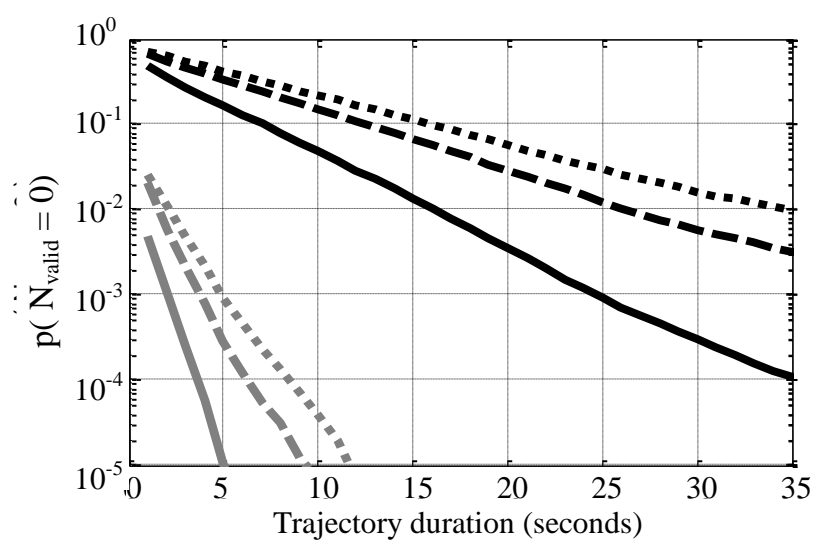

c) L1/E1 MBOC \& L5/E5a BPSK(10) users, HPL = 25 meters.

\begin{tabular}{|c|c|}
\hline $\begin{array}{l}\cdots \cdots \text { WLSR RAIM }\left(\mathrm{P}_{\mathrm{FA}}=5 \cdot 10^{-5}\right) \\
- \text { WLSR RAIM }\left(\mathrm{P}_{\mathrm{FA}}=5 \cdot 10^{-3}\right) \\
\text { - WLSR RAIM modified for ETC }\end{array}$ & $\begin{array}{ll}\text { Grey: } & \text { rural environment } \\
\text { Black: } & \text { urban environment }\end{array}$ \\
\hline
\end{tabular}

Fig. 11. Probability that any of the positions estimated during the user trajectory through a geo-object is not validated by the RAIM $\left(\mathrm{P}_{\mathrm{MD}}=5 \cdot 10^{-5}\right)$.

Let us consider an ETC system that charges a road segment when there is at least one valid position inside the geo-object, that is, $\mathrm{N}_{\mathrm{Th}}=1$ in (1). This threshold has been proved to meet the overcharging requirement providing the lowest probability of missed geo-object [14]. Fig. 11 shows the probability of not 
charging a user that has driven through a road segment as a function of the trajectory duration, a time between independent positions $\left(\mathrm{T}_{\mathrm{c}}\right)$ of $5 \mathrm{~s}$, and various receiver and RAIM configurations. Both GPS \& Galileo receivers have similar performance, so for the sake of clarity only the dual frequency results are plotted. The novel algorithm always provides the best results, reaching a difference of more than one order of magnitude with respect to the classic WLSR RAIM in the dual constellation case for durations longer than $20 \mathrm{~s}$. The classic WLSR RAIM has better performance with a $\mathrm{P}_{\mathrm{FA}}$ of $5 \cdot 10^{-3}$ than of $5 \cdot 10^{-5}$, which means that in this case the gain in the availability rate compensates the loss in the false alarm rate. The reduced visibility penalizes the single constellation performance: while the probability of not charging the road segment with a HAL of $50 \mathrm{~m}$ and after $25 \mathrm{~s}$ of trajectory is $10^{-5}$ for GPS \& Galileo users, it is still over 0.1 for GPS-only users.

\section{CONCLUSION}

GNSS-based ETC systems need to monitor the positioning integrity in order to control the effects of undercharging and overcharging due to positioning failures. With this purpose, two RAIM algorithms have been studied: the WLSR RAIM used in civil aviation and a modified algorithm that, maintaining the $\mathrm{P}_{\mathrm{MD}}$, maximizes the number of valid positions (that is, available RAIM and no fault detected).

The aim of the proposed algorithm is to decrease the rate of undercharging in reduced visibility scenarios like urban environments, assuring the same maximum allowed overcharging risk as the civil aviation RAIM procedure. This objective has been demonstrated by simulations. It has also been shown the improvement of dual constellation receivers in urban environments, which provide undercharging rates several orders of magnitude lower than GPS-only ones.

The proposed design with a variable $\mathrm{P}_{\mathrm{FA}}$ and a fixed HPL can be extended to other existing RAIM algorithms.

\section{REFERENCES}

[1] International Civil Aviation Organization (ICAO), "International Standards and Recommended Practices, Annex 10 to the Convention on International Civil Aviation, Aeronautical Telecommunications, Volume I, Radio Navigation Aids", 6th Edition, July 2006.

[2] RTCA, Inc., "Minimum Operational Performance Standards for Global Positioning System / Wide Area Augmentation System Airborne Equipment", DO-229, Dec. 2006.

[3] Department of Defense USA, "Global Positioning Service Standard Positioning Service Performance Standard", 4th Edition, Sept. 2008.

[4] J. Cosmen-Schortmann, M. Azaola-Saenz, M. A. Martinez-Olague, M. Toledo-Lopez, "Integrity in Urban and Road Environments and its use in Liability Critical Applications," Proceedings of IEEE/ION PLANS 2008, Monterey, CA, May 2008, pp. 972-983.

[5] Racal Tracs Ltd., "Galileo Overall Architecture Definition (GALA). Definition and Sizing For The Safety of Life Market", 6 October 2000.

[6] Directive 2004/52/EC of the European parliament and the council on the interoperability of electronic road toll systems in the Community, Apr. 29, 2004.

[7] B. Pfitzinger, T. Baumann, T. Jestädt, "Analysis and Evaluation of the German Toll System Using a Holistic Executable Specification," hicss, pp.5632-5638, 2012 45th Hawaii International Conference on System Sciences, 2012.
[8] R. Vargic, M. Buncak J. Kacur, "On self-similarity in service triggering in NGN networks using satellite based tolling systems," ELMAR, 2011 Proceedings , vol., no., pp.183-186, 14-16 Sept. 2011.

[9] Velaga, N.R.; Quddus, M.A.; Bristow, A.L.; Yuheng Zheng; , "MapAided Integrity Monitoring of a Land Vehicle Navigation System," Intelligent Transportation Systems, IEEE Transactions on , vol.13, no.2, pp.848-858, June 2012.

[10] Toledo-Moreo, R.; Betaille, D.; Peyret, F.; , "Lane-Level Integrity Provision for Navigation and Map Matching With GNSS, Dead Reckoning, and Enhanced Maps," Intelligent Transportation Systems, IEEE Transactions on, vol.11, no.1, pp.100-112, March 2010.

[11] Toledo-Moreo, R.; Zamora-Izquierdo, M.A.; Ubeda-Miarro, B.; GomezSkarmeta, A.F.; , "High-Integrity IMM-EKF-Based Road Vehicle Navigation With Low-Cost GPS/SBAS/INS," Intelligent Transportation Systems, IEEE Transactions on , vol.8, no.3, pp.491-511, Sept. 2007.

[12] F. van Graas, J. L. Farrell, "Baseline Fault Detection and Exclusion Algorithm," Proceedings of the 49th Annual Meeting of The Institute of Navigation, Cambridge, MA, June 1993, pp. 413-420.

[13] International Organization for Standardization (ISO), "Electronic fee collection - Charging performance - Part 1: Metrics", ISO/TS 174441, First Edition, 2012

[14] D. Salós, "Integrity monitoring applied to the reception of GNSS signals in urban environments", Ph.D. thesis, Institut National Polytechnique de Toulouse, 2012.

[15] B. W. Parkinson, P. Axelrad, "Autonomous GPS Integrity Monitoring using the Pseudorange Residual", NAVIGATION, Vol. 35, No. 2, Summer 1988, pp. 255-274.

[16] R. G. Brown, P. McBurney, "Self-Contained GPS Integrity Check Using Maximum Solution Separation", Navigation: Journal of the Institute of navigation, Vol. 35, No. 1, Spring 1988, pp. 41-54.

[17] M. A. Sturza, "Navigation System Integrity Monitoring using Redundant Measurements", NAVIGATION, Vol. 35, No. 4, Winter 1988-1989, pp. 483-502.

[18] Y.C. Lee, "Analysis of range and position comparison methods as a means to provide GPS integrity in the user receiver", Proceedings of the Annual Meeting of The Institute of Navigation, June, 1986.

[19] R. G. Grover Brown, "A Baseline GPS RAIM Scheme and a Note on the Equivalence of Three RAIM Methods", NAVIGATION, Vol. 39, No. 3, Fall 1992, pp. 301-316.

[20] T. Walter, P. Enge, "Weighted RAIM for Precision Approach," Proceedings of the 8th International Technical Meeting of the Satellite Division of The Institute of Navigation (ION GPS 1995), Palm Springs, CA, September 1995, pp. 1995-2004.

[21] Ober, P.B., "Ways to Improve RAIM/AAIM Availability Using Position Domain Performance Computations," Proceedings of the 1997 National Technical Meeting of The Institute of Navigation, Santa Monica, CA, January 1997, pp. 485-497.

[22] R. G. Brown, G. Y. Chin, "GPS RAIM: Calculation of Thresholds and Protection Radius Using Chi-Square Methods-A Geometric Approach", Global Positioning System: Papers Published in NAVIGATION Volume V, 1998, pp. 155-178.

[23] M.A. Sturza, A.K. Brown, "Comparison of Fixed and Variable Threshold RAIM Algorithms," Proceedings of the 3rd International Technical Meeting of the Satellite Division of The Institute of Navigation (ION GPS 1990), Colorado Spring, CO, September 1990, pp. 437-443.

[24] S. Feng, W.Y. Ochieng, D. Walsh, R. Ioannides, "A measurement domain receiver autonomous integrity monitoring algorithm", GPS Solutions, 2006, vol.10, no.2, pp.85-96.

[25] O. Julien, "Design of Galileo L1F tracking loops", Ph.D. thesis, University of Calgary, Department of Geomatics Engineering, 2005.

[26] D. Salós, C. Macabiau, A. Martineau, B. Bonhoure, D. Kubrak, "Nominal GNSS Pseudorange Measurement Model for Vehicular Urban Applications," Proceedings of IEEE/ION PLANS 2010, Indian Wells, CA, May 2010, pp. 806-815. 


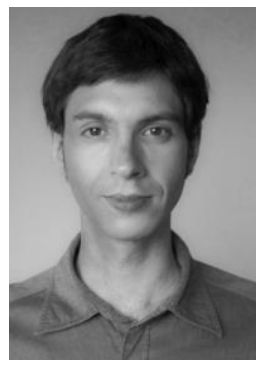

Daniel Salós graduated as a telecommunication engineer in 2006 from the University of Saragossa, Spain, and received his $\mathrm{PhD}$ in 2012 from the University of Toulouse, France.

Since 2008, he has been working in the telecom lab at the ENAC, France. His field of interest is signal processing applied to satellite navigation systems, including GNSS integrity monitoring.

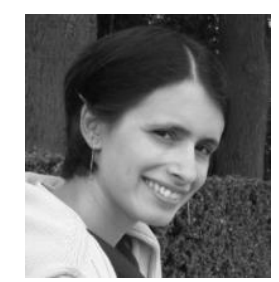

Anaïs Martineau is the head of the Electronics, Electromagnetism and Signal division of ENAC. She graduated in 2005 as an electronics engineer from the ENAC and she received her Ph.D. in 2008 from the University of Toulouse.

Since 2005, she has been working at the Signal Processing and Navigation (SIGNAV) research group of the TELECOM lab of ENAC where she carries out research on integrity monitoring techniques.

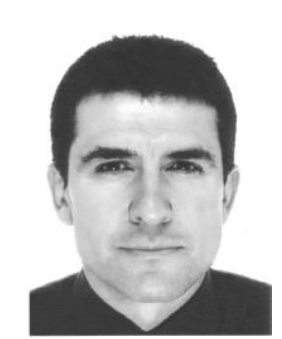

Christophe Macabiau graduated as an electronics engineer in 1992 from the ENAC (Ecole Nationale de l'Aviation Civile) in Toulouse, France. Since 1994, he has been working on the application of satellite navigation techniques to civil aviation. He received his Ph.D in 1997 and has been in charge of the signal processing lab of ENAC since 2000, where he also started dealing with navigation techniques for urban navigation. He is currently the head of the TELECOM lab of ENAC, that includes research groups on signal processing and navigation, electromagnetics and data communication networks.

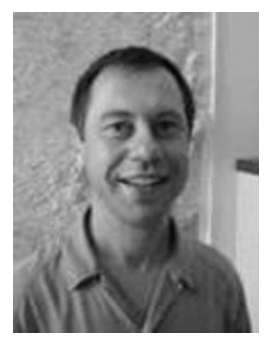

Bernard Bonhoure graduated as an aeronautic engineer from ENSICA in Toulouse (ISAE).

He joined CNES in 1989, he has worked on several successful space programmes such as TOPEX/POSEIDON, SPOT, ENVISAT, JASON. As a navigation system expert, he is now involved in many activities linked to GNSS satellite positioning and performances.

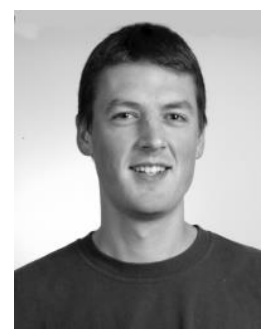

Damien Kubrak graduated in 2002 as an electronics engineer from ENAC, Toulouse, France.He received his Ph.D. in 2007 from ENST Paris, France.

Since 2006, he is working at Thales Alenia Space, Toulouse, France, where he is involved in land vehicle navigation, GNSS signal processing and hybridization for seamless positioning, assisted GNSS and mobile phones performance assessment. 